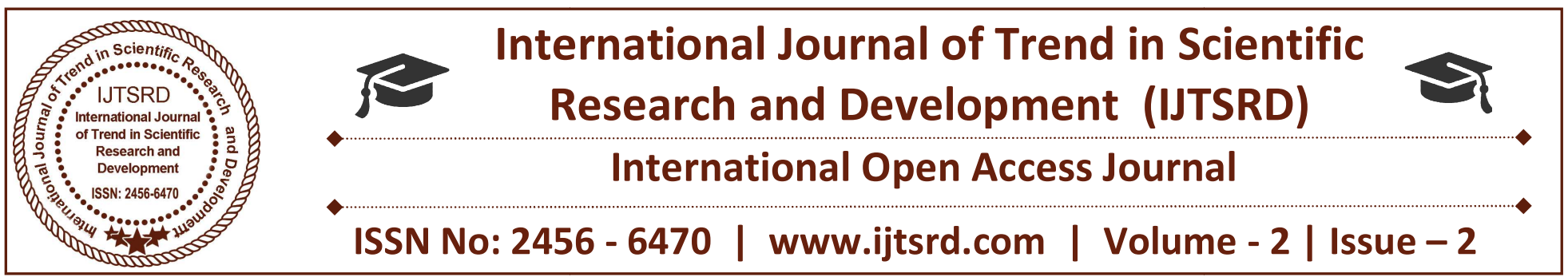

\title{
Effect of Deep Cryogenic Treatment on the Tensile Behavior of AISI 8620 Gear Steel
}

\author{
Prasenjit Ghosh \\ Associate Professor, College of Military Engineering, \\ Pune, Maharashtra, India
}

\section{ABSTRACT}

Life expectancy of mechanical systems is always dependent on the most critical component of the system. Gears represent the most highly stressed parts of a heavy vehicle; these are typically made of AISI 8620 steel. This paper investigates the influence of cryogenic treatment on the tensile properties of hardened tempered AISI 8620 steel. In the current research study, specimens of gear steel (AISI 8620) were hardened at $1193 \mathrm{~K}$, tempered at $473 \mathrm{~K}$ and then cryogenically treated at $88 \mathrm{~K}$ followed by soft tempering in the oven at $373 \mathrm{~K}$ for $1 \mathrm{hr}$ to relieve cooling stresses. A comparative study on the effects of deep cryogenic treatment (DCT) on hardened tempered specimens and conventional heat treated specimens was made by means of tension testing. This test was conducted as per ASTM standard E 8M. The present results confirms that the tensile behavior is marginally reduced after cryogenic treatment for AISI 8620 steel when compared with conventional hardened tempered steel. Stereographic image analysis of the fracture surface indicates the presence of dimples and flat regions are more common in DCT - processed material.

Keywords: Deep cryogenic treatment, Stereographic image analysis, Tensile strength, AISI 8620

\section{Introduction}

Over the past few decades, interest has been shown in the effect of low-temperature treatment on the performance of steels. Low-temperature treatment is generally classified as either 'sub-zero treatment' at temperatures down to about $193 \mathrm{~K}\left(-80^{\circ} \mathrm{C}\right)$ or deep cryogenic treatment at liquid nitrogen temperature (- $\left.196^{\circ} \mathrm{C}\right)$ (1). The basic cryogenic treatment consists of gradual cooling of the component until the defined temperature, holding it for a given time(soaking time) and the progressively leading it back to room temperature, and tempering it to decrease the brittleness of the martensite(2). Zhirafar et al. (3) made an experimental investigation on the effects of cryogenic treatment on the mechanical properties and microstructures of AISI 4340 steel. It was shown that in general, hardness and fatigue strength of the cryogenically treated specimens were a little higher whereas the toughness of the cryogenically treated specimens was lower compared to that of the conventionally treated steel. Jaswin et al. (4) studied the effects of cryogenic treatment on the tensile behavior of En-52 and 21-4N valve steels at room and elevated temperatures. Both the materials were subjected to shallow and deep cryogenic treatment and the tensile results were compared with conventional heat treated steel. The ultimate tensile strength and average yield strength showed improvement over conventionally treated steel whereas there is marginal reduction in percentage elongation in cryotreated steels. Scanning electron microscopy has revealed that precipitation of fine secondary carbides are responsible for improved mechanical strength and reduced percentage elongation in shallow and deep cryogenically treated steel. Bensely et al. (5) analyzed the role of cryogenic treatment on the tensile behavior of case carburized 815M17 steel. These steels are used as crown wheels and pinion of heavy vehicles. Tensile samples of 815M17 steel were prepared as per ASTM E $8 \mathrm{M}$ standards and a comparative study was made on the 
effects of deep cryogenic treatment (DCT), shallow cryogenic treatment (SCT) and conventional heat treatment $(\mathrm{CHT})$ by means of tension test. From the experimental results it is concluded that mechanical strength is marginally reduced after cryogenic treatment (both DCT and SCT) when compared with conventionally heat treated steel.

To the best of the knowledge there is no data available on the role of deep cryogenic treatment on the tensile behavior of AISI 8620 steel.

\section{Methods and Experimental Procedure}

\subsection{Materials}

The material selected for the present investigation was alloy steel AISI 8620. The $50 \mathrm{~mm}$ diameter steel bar was received in the hot rolled condition. The chemical composition of the procured steel was determined using an Optical Emission Spectroscope and is reported as $0.20 \mathrm{C}, 0.24 \mathrm{Si}, 0.88 \mathrm{Mn}, 0.63 \mathrm{Cr}, 0.45 \mathrm{Ni}$, $0.21 \mathrm{Mo}, 0.021 \mathrm{~S}, 0.016 \mathrm{P}$ (wt \%).

\subsection{Heat treatment and Cryogenic treatment}

A group of specimens were subjected to conventionally hardening which includes austenitizing at $920^{\circ} \mathrm{C}$ for $25 \mathrm{~min}$ in a muffle furnace, followed by oil quenching. Then tempering was carried out at $200^{\circ} \mathrm{C}$ in an oven. Deep cryogenic treatment (DCT) consisted of slowly cooling these tempered samples in a cryogenic processor at $-185^{\circ} \mathrm{C}$ and holding at this temperature for $4 \mathrm{hr}, 8 \mathrm{hr}, 12 \mathrm{hr}, 16 \mathrm{hr}, 20 \mathrm{hr}$ and gradually bringing the specimens back to room temperature. Post subzero treatment to all specimens were subjected invariably to soft tempering in the oven at $100^{\circ} \mathrm{C}$ for $1 \mathrm{hr}$ to relieve cold stresses.

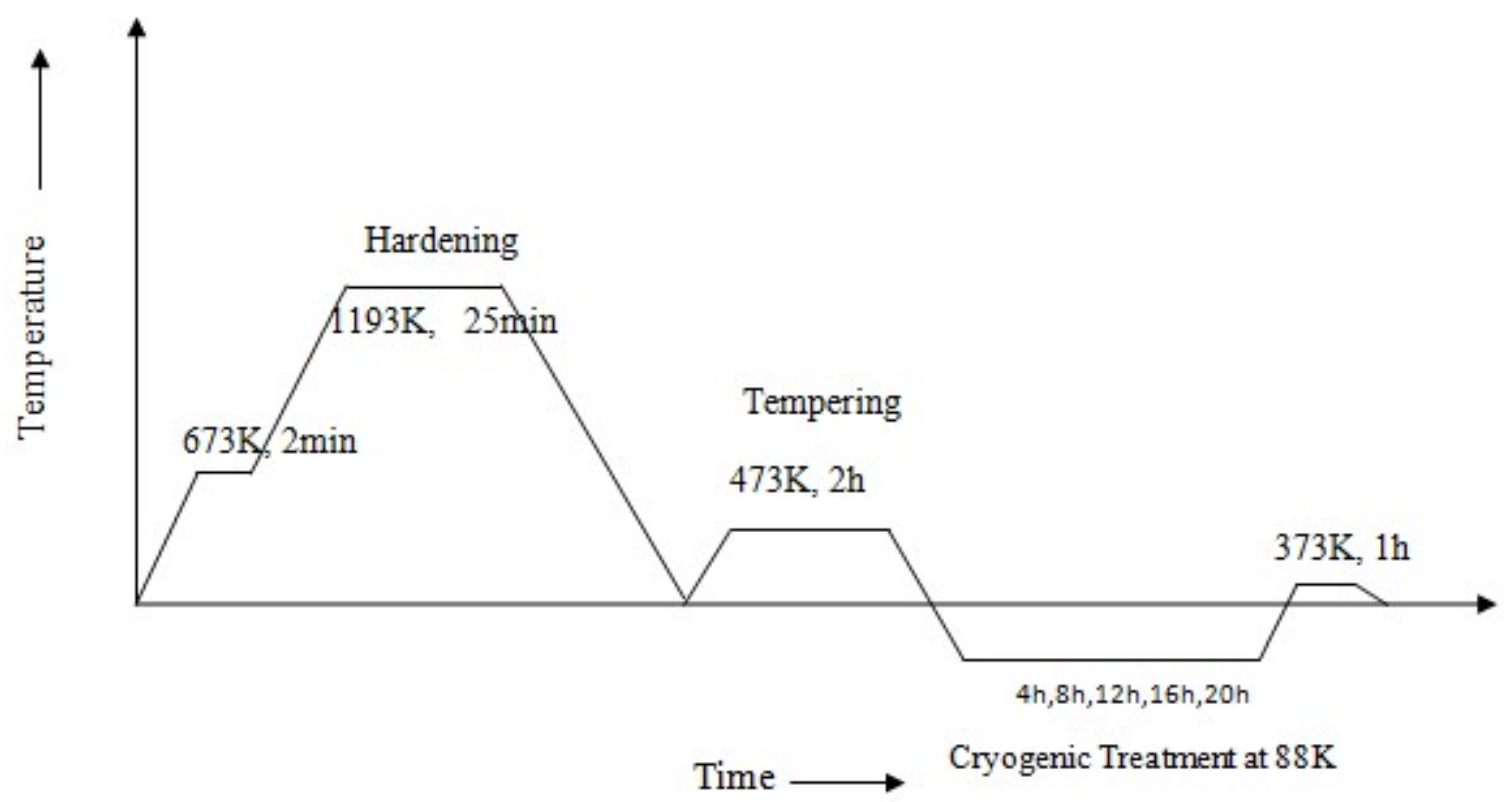

Fig 1: Schematic T-T diagram illustrates processing steps for Hardening, Tempering and cryotreatment cycle employed on AISI 8620 steel

\subsection{Hardness Measurement}

The hardness measurement was done on Rockwell hardness testing machine using C-scale. The specimens were cut and ground to maintain height to diameter ratio equal to one. Initially a minor load of $10 \mathrm{~kg}$ was applied to seat the diamond indenter. Subsequently major load of $150 \mathrm{~kg}$ was applied for $15 \mathrm{sec}$ and reading on the dial gauge was recorded for measurement of hardness. An average of three readings was taken.

\subsection{Tensile testing}

Parts of structures, machines or devices are invariably subjected to uniaxial tension load. The behaviour of a material under simple uniaxial tension is called tensile behaviour. Tensile test was conducted on FIE make Universal Tensile Testing machine having machine capacity of $600 \mathrm{KN}$ at NABL approved Laboratory. The size and geometry of the specimens as per ASTM E8-04 standard is shown in Fig.2. 


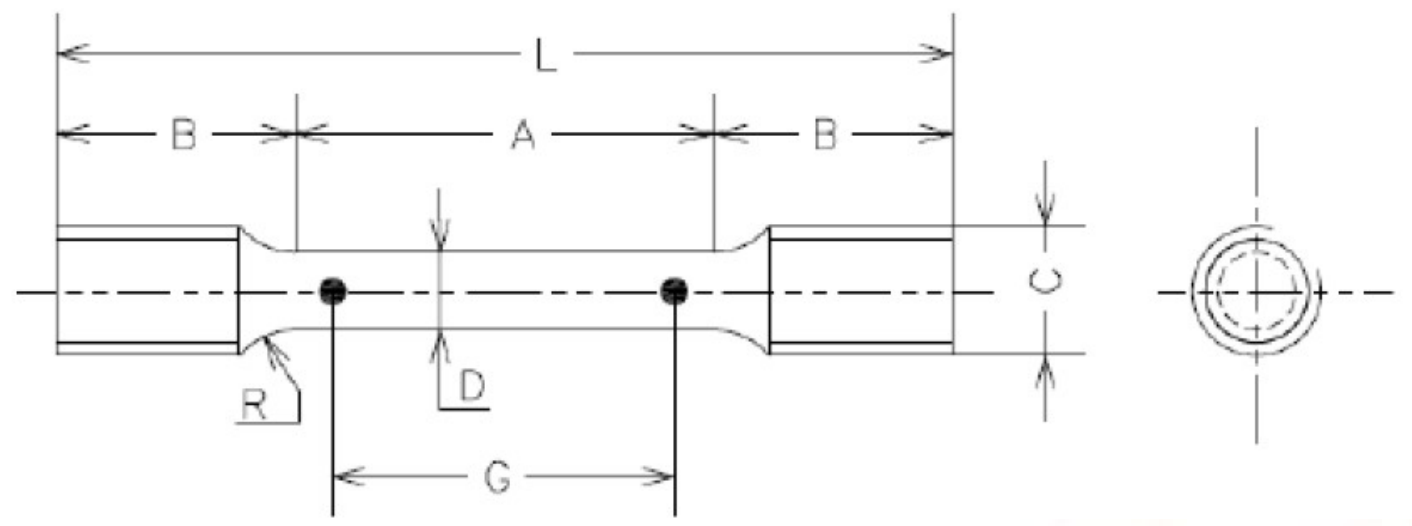

Fig.2: Drawing of Tensile testing specimen (ASTM E8-04)

Table 1.0: Dimensions of tensile test specimen

\begin{tabular}{|l|l|l|l|l|}
\hline $\begin{array}{l}\text { Diameter } \\
\text { (D) } \mathrm{mm}\end{array}$ & $\begin{array}{l}\text { Gage } \\
\text { length } \\
\text { (G) } \mathrm{mm}\end{array}$ & $\begin{array}{l}\text { Radius } \\
\text { of } \\
\text { fillet(R) } \\
\mathrm{mm}\end{array}$ & $\begin{array}{l}\text { Parallel } \\
\text { length } \\
\text { (A) } \mathrm{mm}\end{array}$ & $\begin{array}{l}\text { Overall } \\
\text { length } \\
\text { (L) } \mathrm{mm}\end{array}$ \\
\hline 8.75 & 35 & 12 & 40 & 102
\end{tabular}

The specimens are placed in the grip of the tensile testing machine at a specified grip separation. Initial gauge length of $35 \mathrm{~mm}$ was marked on the uniform portion of the specimen. The extensometer, calibrated to ASTM E83 requirements, was on a $25 \mathrm{~mm}$ clip-on device. After setting the specimen on the holder the machine is switched on. The load is applied to the specimen along the uniaxial direction at a strain rate of $1.6 \mathrm{~mm} / \mathrm{min}$ upto yield point and $12.7 \mathrm{~mm} / \mathrm{min}$ till fracture. The graph sheet mounted on the drum plotter shows the tensile and $0.2 \%$ proof stress values. The percentage elongation of the specimen after fracture is obtained by putting the specimen back together on the elongation gauge.

\subsection{Results and discussions}

Mechanical strength of a material is its ability to bear load without undergoing any undue distortion or failure. The test performed for this purpose is referred to as tensile test. The stress vs. strain graphs and results of the tensile test for the hardened tempered (HT) and hardened tempered and cryotreated ( HTC16) specimens are depicted in Figs. 3- 5 and Table 2.0 respectively.

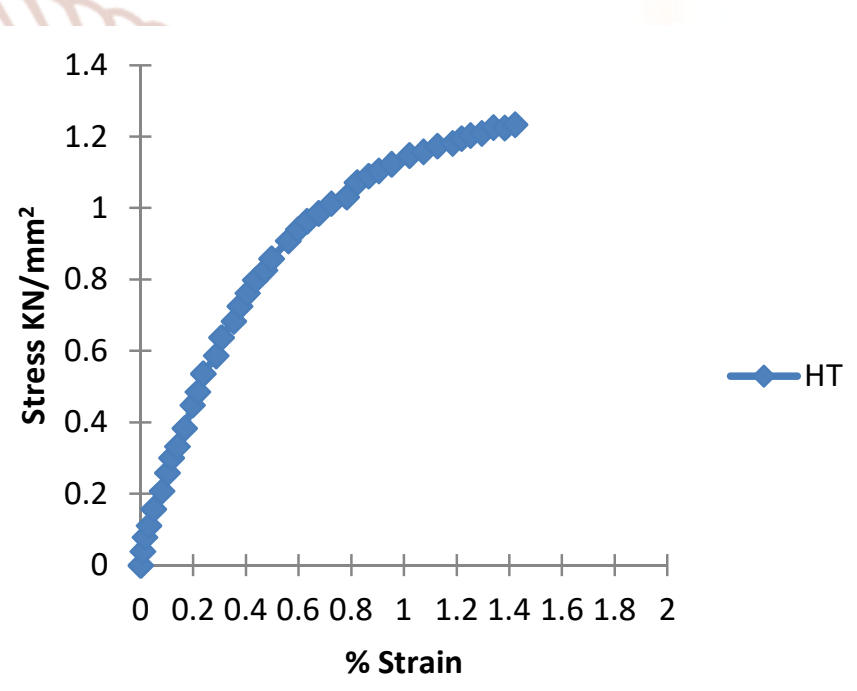

Fig. 3: Stress-strain curve for Hardened Tempered (HT) steel

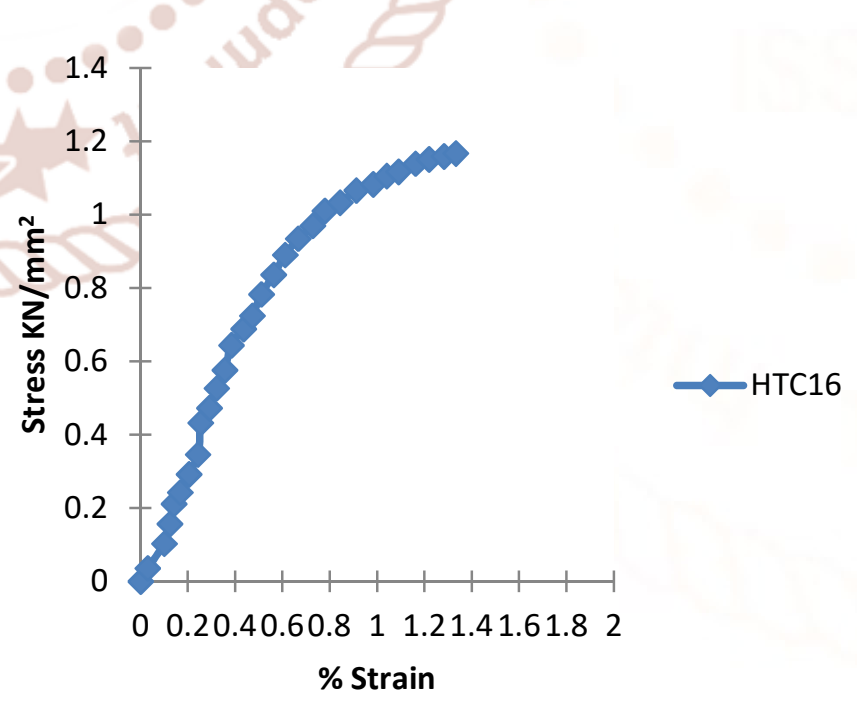

Fig. 4: Stress-strain curve for Hardened Tempered Cryotreated for 16h (HTC16) steel 


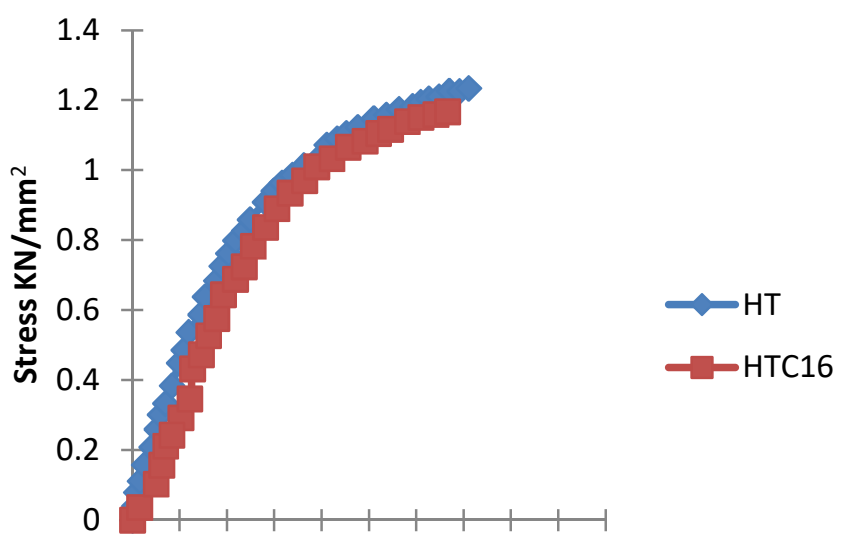

$\begin{array}{llll}0 & 0.20 .40 .60 .8 & 1 & 1.21 .41 .61 .8\end{array}$

$\%$ Strain

Fig. 5: Combined Stress-strain curve for Hardened Tempered (HT) Hardened Tempered Cryotreated (HTC16) steel

Table 2.0: Comparison of tensile test results under different heat treatment conditions

\begin{tabular}{|c|c|c|}
\hline Tensile Properties & $\mathrm{HT}^{2}$ & HTC16* \\
\hline $\begin{array}{l}\text { Ultimate Tensile } \\
\text { Strength }\left(\mathrm{N} / \mathrm{mm}^{2}\right)\end{array}$ & 1352 & 1296 \\
\hline $\begin{array}{l}0.2 \% \\
\text { Stress }\left(\mathrm{N} / \mathrm{mm}^{2}\right)\end{array}$ & 1092 & 1119 Rest \\
\hline $\begin{array}{l}\text { Percentage } \\
\text { Elongation }(\%)\end{array}$ & 15.6 & 14.1 \\
\hline $\begin{array}{l}\text { Reduction } \\
\text { Area }(\%)\end{array}$ & 53.5 & 55.0 \\
\hline Hardnes & 41.1 & 7.0 \\
\hline
\end{tabular}

* Average of three specimens

The ultimate tensile strength of the HT steel has an average value of $1352 \mathrm{MPa}$ whereas for HTC16 steel it has an average value of $1296 \mathrm{MPa}$. The $0.2 \%$ proof stress amounts to an average value of $1092 \mathrm{MPa}$ for the HT steel and $1119 \mathrm{MPa}$ for HTC16 steel. The HTC16 steel exhibits a marginal increase by $2.47 \%$ in $0.2 \%$ proof stress over HT steel. On comparing the results of the percentage elongation, HTC16 show a lesser elongation than HT. The small reduction in the percentage elongation of the cryo-treated samples indicates a minor reduction of ductility. The reduction in the percentage elongation is attributed to the increase in hardness and decrease in wear rate and transformation of retained austenite into martensite which is evident from the microstructural study and retained austenite analysis conducted earlier.

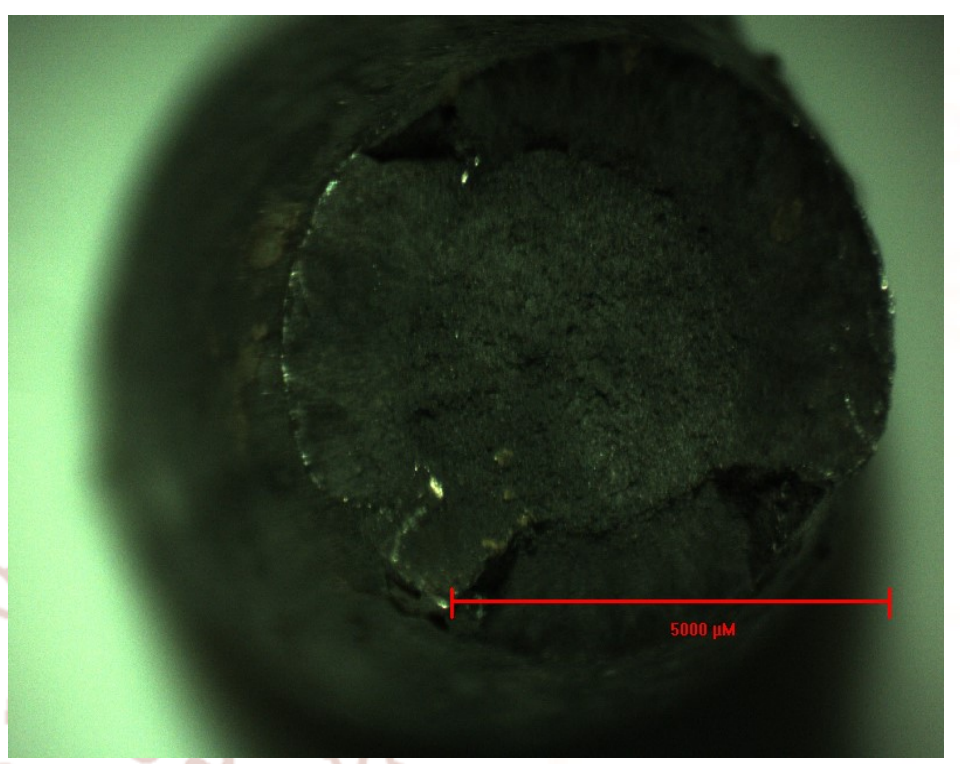

Fig. 6: Stereoscopic image of the fracture surface of HT specimen (10X)

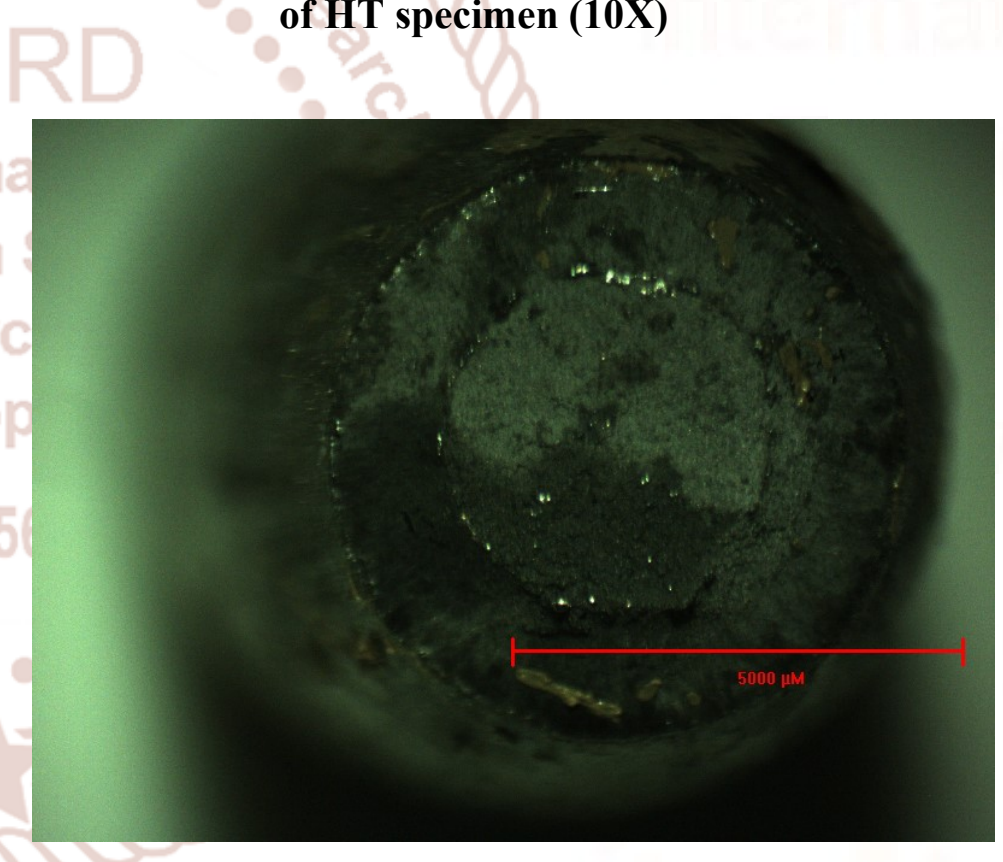

Fig.7: Stereoscopic image of the fracture surface of HTC 16 specimen (10X)

Fig.6 and Fig.7 shows the stereoscopic examination of the fracture surface of hardened, tempered steel using magnification of $10 \mathrm{X}$. From the macroscopic view point, the fracture surface of HTC16 appears to be more brittle as compared to HT. This may be due to very little ductility of $14.1 \%$ in HTC16 steel as compared to $15.6 \%$ in HT steel. Figure 7 also reveals that fracture surface area of HTC16 steel is less as compared to fracture surface area of HT steel (Fig.6). This is also corroborated by the tensile test results. The percentage reduction in area in HT steel was 
found to be $53.5 \%$ whereas in HTC16 steel, it was found to be $55 \%$.

\section{Conclusion}

The study concludes that the deep cryogenic treatment diminishes the tensile strength of AISI gear steel. There is minor reduction in the ductility of cryotreated steel as compared to that of conventional hardened tempered steel. Streoscopic examination of the tensile fracture surface reveals more dimples and flat regions in cryotreated steel as compared to conventional heat treated steel.

\section{Acknowledgements}

The author gratefully acknowledges his indebtedness to the AICTE New Delhi, Govt. of India for providing funds to carry out the entire research work.

\section{References}

1. P. Baldissera and C. Delprete 'Deep cryogenic treatment: A Bibliographic Review', The open Mechanical Engineering Journal, 2008, 1-11.

2. A. Joseph Vimal, A. Bensely, D. Mohan Lal and K. Srinivasan ' Deep cryogenic treatment improves wear resistance of En-31 steel.' Materials and Manufacturing Processes, 23; (2008), 369-376.

3. S. Zhirafar, A. Rezaeian, M.Pugh 'Effect of cryogenic treatment on the mechanical properties of 4340 steel.' Journal of Materials Processing technology 186 (2007) 298-303.

4. M.A. Jaswin, D.M.Lal 'Effect of cryogenic treatment on the tensile behavior of EN-52 and 21-4N valve steels at room and elevated temperatures.' Materials and Design 32 (2011) 2429-2437.

5. A. Bensely, D. Senthil kumar, D.Mohan Lal ‘ Effect of cryogenic treatment on tensile behavior of case carburized steel -815M17.' Materials Characterization 58 (2007) 485-491. 